\title{
Exserohilum rostratum (Drechsler) Leonard y Suggs.
}

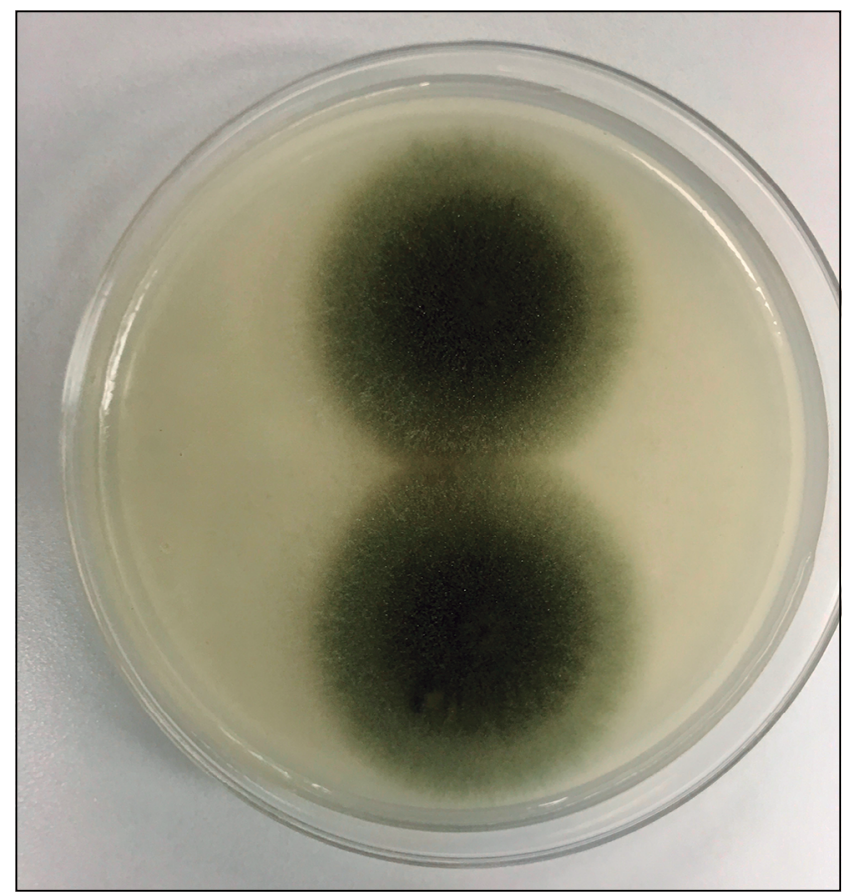

Figura 1. Colonia en agar papa zanahoria a los 5 días de cultivo a $37^{\circ} \mathrm{C}$.

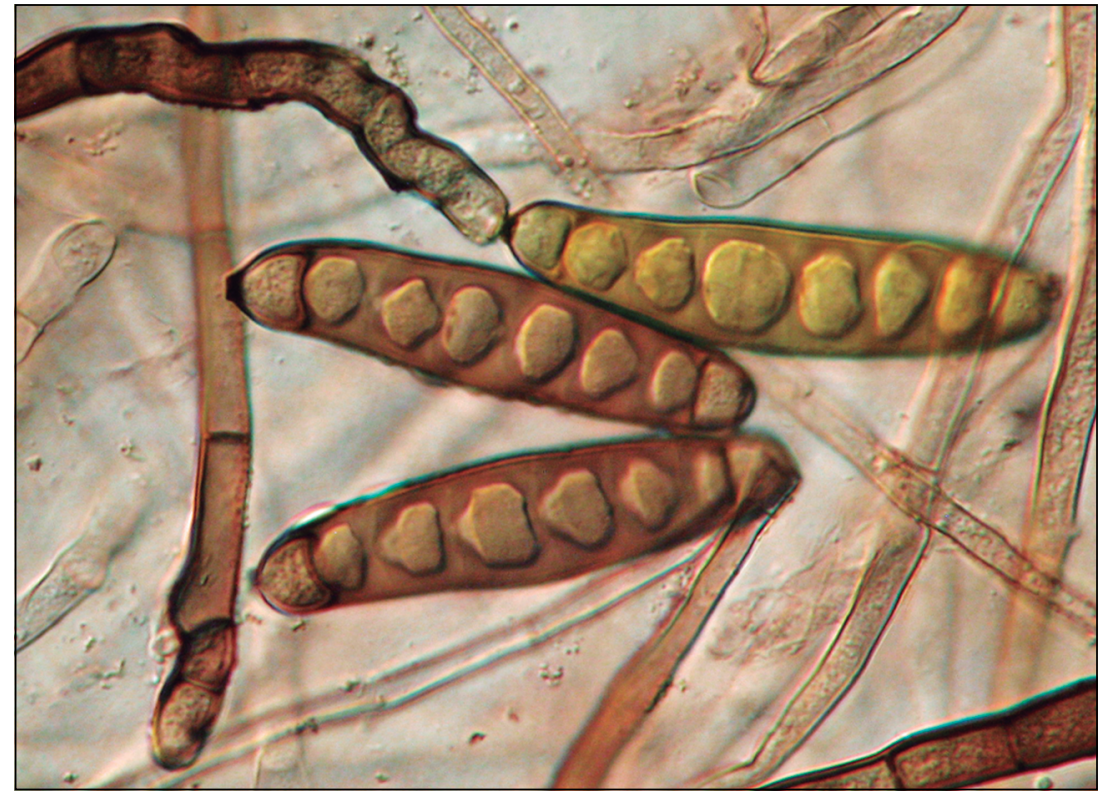

Figura 2. Se observan conidióforos flexuosos y rectos, macroconidios ligeramente curvados multiseptados e hilum prominente. 


\section{Exserohilum rostratum (Drechsler) Leonard y Suggs}

El género Exserohilum (Setosphaeria como teleomorfo) está constituido por especies de hongos filamentosos dematiáceos ubicuos, comunes de aislar en zonas con abundante pasto, vegetales y cereales (avena, maíz, caña de azúcar), tanto como saprótrofos como fitopatógenos. La especie tipo es E. turcicum, causa del tizón de la hoja del maíz. Es frecuente confundir este género con Bipolaris spp y Dreschlera spp debido a que se encuentran estrechamente relacionados y su morfología puede parecer similar.

Exserohilum rostratum es una especie cosmopolita fitopatógena que puede afectar el trigo, la caña de azúcar, el maíz y el sorgo. Sus conidios se dispersan principalmente a través de la lluvia y el viento. Puede provocar feohifomicosis, tanto en animales como en seres humanos, describiéndose casos de queratitis, artritis, meningitis, infección rino-sinusal, pulmonar o diseminada, especialmente en pacientes inmunocomprometidos. También se le ha asociado con cuadros de alergias, rinitis y descompensación en pacientes con asma o EPOC.

En el año 2012, los CDC reportaron un brote de meningitis y otras infecciones profundas asociadas a inyecciones de metilprednisolona contaminadas E. rostratum. El brote afectó a 753 pacientes de 20 estados distintos, tanto en pacientes ambulatorios como hospitalizados, 64 de ellos fallecieron.

Macroscopía: las colonias son de color gris a marrón negruzco, de textura semejante a la gamuza, floculada, con un reverso negro oliváceo (Figura 1).

Microscopía: desarrolla conidióforos de hasta $230 \mu \mathrm{m}$ de largo y 5-8 $\mu \mathrm{m}$ de ancho, café, lisos y geniculados, con células conidiógenas poliblasticas simpodiales. Los macroconidios miden hasta $128 \mu \mathrm{m}$ de largo y $23 \mu \mathrm{m}$ de ancho, son rectos a fusiformes que se forman apicalmente en un poro, multiseptados, con un hilum protruido característico (Figura 2 ).

Fisiología: suele crecer a $37^{\circ} \mathrm{C}$ a diferencia de otras especies del género.

Identificación molecular: se recomienda la secuenciación ITS y D1 / D2 para la identificación correcta de las especies.

Tratamiento: se recomienda como régimen primario voriconazol y como alternativa anfotericina B liposomal. En caso de usar voriconazol se debe medir los niveles plasmáticos al quinto día de tratamiento y luego una vez por semana con el objetivo de tener un valor entre 2 a $5 \mu \mathrm{g} / \mathrm{ml}$, para evitar principalmente la neuro y hepatotoxicidad.

\section{Referencias bibliográficas}

1.- De Hoog G S, Guarro J, Gené J, Figueras M J. Atlas of Clinical Fungi. Utrecht/Reus: Westerdijk Fungal Biodiversity Institute; 2019.

2.- Piontelli E. El género Exserohilum Leonard \& Suggs. Manual de microhongos filamentosos comunes I. 3.a ed. Valparaíso; 2015. pp: 257-60.

3.- MICOBANKDATABASE. Fungal databases, nomenclature \& species banques Disponible en: http://www.mycobank.org/defaultinfo. aspx?Page=Home. Fecha de acceso: 5 de enero de 2020.

4.- Centers for Disease Control and Prevention. Multistate Outbreak of Fungal Meningitis and Other Infections - Resources for Clinicians. Disponible en: https://www.cdc.gov/hai/outbreaks/clinicians/index.html. Fecha de acceso:

Rodrigo Cruz Choappa ${ }^{1}$ y Eduardo Piontelli ${ }^{1}$ ${ }^{I}$ Laboratorio de Micología, Universidad de Valparaíso.

Correspondencia a: Rodrigo Cruz Choappa rodrigo.cruz@uv.cl 